\title{
Economic evaluation of air pollution impacts on human health: an overview of applied methodologies
}

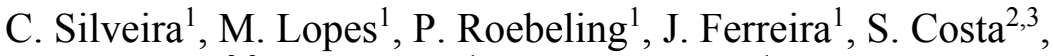 \\ J. P. Teixeira ${ }^{2,3}$, C. Borrego ${ }^{1} \&$ A. I. Miranda ${ }^{1}$ \\ ${ }^{1}$ CESAM and Department of Environment and Planning, \\ University of Aveiro, Portugal \\ ${ }^{2}$ Epidemiology Research Unit, Institute of Public Health, \\ University of Porto, Portugal \\ ${ }^{3}$ National Institute of Health, Environmental Health Department, \\ Portugal
}

\begin{abstract}
Air pollution is a worldwide problem with broadly known harmful effects on health and environment. A great research challenge lies in quantifying the intensity of these adverse effects as well as the associated external costs. To this end, several methodologies involving exposure-response relationships and economic evaluation of externalities have been developed. A literature review of existing methodologies to estimate air pollution impacts on human health and subsequent external costs has been performed aiming to identify strengths and major gaps in current knowledge. The most common practice is to estimate health impacts taking into account morbidity (disability-adjusted life years due to episodes of cardiovascular and respiratory diseases) and mortality (e.g. years of life lost due to lung cancer) indicators. For the quantification of the resulting external costs, a monetary valuation of the extent of damage, grounded in treatment/remediation costs, is applied.

Notwithstanding the significant efforts to improve the economic evaluation of air pollution impacts, there is some controversy on damage cost estimates. For example, the monetary valuation is not a straightforward procedure as many of the impacts have no market value. In addition, it is increasingly recognized that
\end{abstract}


willingness-to-pay approaches are needed to assess the value attributed to avoid human health impacts and damages.

This paper describes the approach developed within the context of the ongoing MAPLIA research project to assess the costs related with air pollution impacts on health in a Portuguese urban area, and to be used in the MAPLIA integrated decision support system for air quality management.

Keywords: air pollution, damage, health impacts, external costs, willingness-topay.

\section{Introduction}

The definition of air quality management strategies can be aided by effectiveness, cost-effectiveness and cost-benefit assessments of emission reduction scenarios [1]. Effectiveness studies assess the extent to which these scenarios result in emission reductions and associated air quality improvements. Cost-effectiveness studies assess, in addition, the monetary costs asociated with the implementation of these scenarios and, hence, faciliate the identification of those scenarios that achieve emission reductions and/or air quality improvements at least cost. Finally, cost-benefit studies assess, moreover, the monetary benefits associated with air quality improvements and, therefore, facilitate the identification of those scenarios that provide largest welfare gains.

Monetary costs associated with the implementation of emission reduction measures and scenarios are, generally, estimated on the basis of measure application rates and corresponding unit costs (e.g. following the GAINS methodology [2]). The estimation of the monetary benefits from emission reduction measures and scenarios is, however, more complex. Economic evaluation studies employ several techniques to estimate the monetary costs/benefits that result from changes in air quality [3]. The costs associated with air pollution are known as negative externalities, involving external costs to repair a given reference situation or avoid the deterioration of social welfare and human well-being. A comprehensive economic evaluation starts with a clear identification of the involved air pollutants and their effects on different damage categories including health impacts, building and material damages, crop losses, and biodiversity and ecosystem degradation [4]. Among these different damage categories, health impacts caused by air pollution contribute to the largest part of the external cost estimates. This finding is shared by public health experts that link air pollution, even at current ambient levels, to worsened morbidity (especially respiratory and cardiovascular diseases) and premature mortality (e.g. years of lost life) [5].

This study presents a review on the available methodologies for the quantification of air pollution-related health impacts and subsequent external costs, which will be used for the assessment of different emission reduction scenarios designed in the Portuguese research project MAPLIA (http://projetomaplia.web.ua.pt/). To achieve this goal, the following specific objectives are established: i) identify the relevant physical impacts and establish exposureresponse functions that allow to calculate the number of attributable cases; and ii) 
identify the different cost components related to the impacts and estimate their value in monetary terms.

Arising this research, weaknesses and needed improvements in the economic evaluation of air pollution impacts on human health are discussed.

\section{Concepts and methodology to estimate external costs of air pollution}

The concept of external costs is analysed by relating atmospheric emissions from the main activity sectors to air quality state, associated physical impacts and, finally, the monetary value of this impact (Figure 1). In this sense, the Impact Pathway Approach (IPA), designed within the ExternE (External Costs of Energy) project [5], is often used by the scientific community to obtain damage estimates for different categories of impacts. Moreover, this approach allows the cost-benefit analysis of policy options considered for air quality management [6] understanding as benefit the avoided external costs when improving air quality. With this purpose, Miranda et al. [7] based their research on European air quality plans, reviewed the assessment capabilities and modelling tools to evaluate the effects of emission abatement strategies improving air quality.

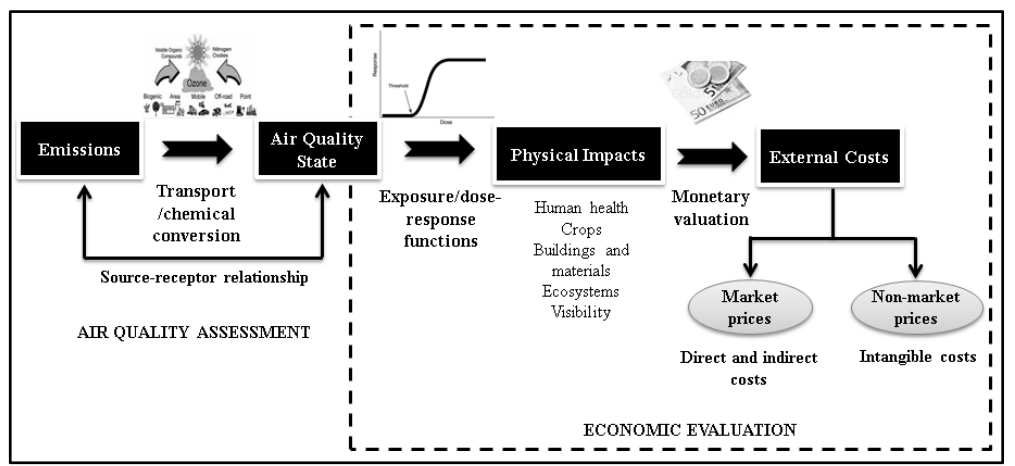

Figure 1: Different stages leading to the evaluation of emission impacts.

The health impacts arising from air pollution can be estimated using as support the work by Costa et al. [8] that describes how health can be integrated in air quality assessment through exposure and dose-response functions. Thereby, emphasis will be given to the following components: physical impacts considering different health indicators, and external costs to remediate the occurred damages or prevent productivity losses and pain/suffering.

To quantify the extent of these impacts, the IPA has been applied, preferably from a bottom-up prespective. This methodology requires epidemiological information on exposure-response functions (effect estimates) and health outcome frequencies (mortality and morbidity, prevalence, incidence or person-days) which combined with the population exposure to air pollution provides the number of attributable cases/days (Eqn. 1). 


$$
\Delta \mathrm{R}_{\mathrm{i}}=\mathrm{I}_{\text {ref }} \times \mathrm{CRF}_{\mathrm{i}, \mathrm{p}} \times \Delta \mathrm{C}_{\mathrm{p}} \times \text { pop }
$$

where:

$\Delta \mathrm{R}_{\mathrm{i}}-$ Response as a function of the number of the unfavorable implications (cases, days or episodes) over all health indicators $(i=1, \ldots, n)$ avoided or not;

$\mathrm{I}_{\mathrm{ref}}$ - Baseline mobidity/mortality annual rate;

$\mathrm{CRF}_{\mathrm{i}, \mathrm{p}}$ - Correlation coefficient between the pollutant $\mathrm{p}$ 's concentration variation and the probability of experiencing or avoiding a specific health indicator i (i.e. Relative Risk);

$\Delta \mathrm{C}_{\mathrm{p}}$ - Change in the pollutant p's concentration;

pop - Population units exposed to pollutant $p$.

The pollutants concentration and population data are combined to estimate the human exposure, and then, the impact coefficient $\left(\mathrm{CRF}_{\mathrm{i}, \mathrm{p}}\right)$ is calculated using an exposure-response function (ERF), expressed as Relative Risk (RR) derived from epidemiological studies. The baseline morbidity/mortality rate $\left(\mathrm{I}_{\text {ref }}\right)$ is often incorporated in the CRF $[5,9,10]$.

The resulting physical impacts are translated into monetary values (i.e. external costs), in order to be properly considered in the decision-making process. These external costs are generally divided in three broad categories: direct costs (health care and non-health care costs), indirect costs (productivity and production losses) and intangible costs (pain and suffering). Direct and indirect costs are thereby estimated on the basis of market prices, while intangible costs are based on nonmarket prices (see Section 3.2) [11, 12].

\section{Economic evaluation of air pollution-related health impacts}

The economic evaluation of external costs starts with a clear identification of the involved air pollutants and their health effects. Underlying these issues, a large variety of environmental factors must be previously analysed, such as overall pollution levels, characterization of emission sources (e.g. relative contribution by activity sector, geographic location and height of release points), population structure (e.g. density and spatial distribution, age groups) and the meteorological conditions influencing transport, dispersion and chemistry of air pollutants [6].

This section presents a summarized description of the methodological assumptions to quantify health impacts (Section 3.1) and subsequent external costs (Section 3.2) resulting from air pollution. Thereafter, an overview of research studies underpinning these methodologies is presented (Section 3.3), in particular with respect to the key impact functions and associated external costs.

\subsection{Physical impacts}

Physical health impacts caused by exposure to air pollutants are expressed through morbidity and mortality indicators related with respiratory and cardiovascular diseases. Regarding the most common air pollutants (particulate matter, ozone, sulphur dioxide and nitrogen oxides), the following health effects are often felt: 
- reduction in life expectancy due to acute and chronic mortality;

- chronic effects on morbidity, such as bronchitis and cough in children and asthmatics;

- and acute effects on morbidity, namely respiratory and cardiovascular hospital admissions, asthma episodes and restricted activity.

This cause-effect relationship is significantly stronger for particulate matter (PM) $[11,13]$, and thus their effects are better documented and quantified $[14,15]$.

The quantification of the extent of these health impacts is based on the correlation between exposure and effect, varying depending on the specificity and availability of data and models [6]. Often, due to unavailability/lack of epidemiological studies based on country's own data, the ERF used are taken from international epidemiological studies regarded as reference studies by the scientific community. In this context, ERF based on a relative risk model have been applied to translate air concentrations in health impacts. According to numerous studies, certain vulnerable groups within population (e.g. elderly people, children, and those with underlying diseases) have shown a greater risk of being affected by air pollutants $[8,11,16]$.

These ERF may be linear or non-linear and contain or not threshold exposure values. Nevertheless, the IPA assumes that this cause-effect relation is linear, in the form of a Poisson regression, which usually does not reflect the real situation as there is a threshold exposure value above which the physical impact is no longer felt. Therefore, this methodology is considered more appropriate for situations in which the increase in pollutant emissions does not affect the marginal cost of the resulting impacts [17].

Adverse health effects occur often within a short lag after exposure (short-term exposure) resulting in acute effects. Nevertheless it is important to consider also the cumulative exposure over time (long-term exposure) resulting in chronic effects [8]. Short-term exposure studies usually explore time-series of hourly and daily changes in air pollution, and daily death counts or cause-specific hospitalizations [14]. Furthermore, the acute exposure assessment reveals great use to estimate the number of attributable cases to changes in air pollution in the immediately preceding days, aggregated over the entire year [18]. However, these studies only capture one part of the overall problem, since as shown by long-term studies the mortality risk is increased due to chronic exposure to air pollution [12, 16]. To design the overall effect of air pollution on life expectancy, cohort studies have been used to provide results in terms of mortality risk changes (age-specific death rates) per unit change in the pollutant concentration. For impact estimation, this change in mortality risk can be most reliably represented by using life table methods to express mortality impacts in the target population, translated in terms of life expectancy changes and/or in total life-years gained or lost for a given air pollution scenario [18].

\subsection{External costs}

The economic valuation of health impacts arising from air pollution is, generally, based on the cost-of-illness (COI) approach [11,19]. According to the COI 
approach, total health costs $\left(\mathrm{C}_{\text {health }}\right)$ are determined by the sum of direct $\left(\mathrm{C}_{\text {direct }}\right)$, indirect $\left(\mathrm{C}_{\text {indirect }}\right)$ and intangible $\left(\mathrm{C}_{\text {intangible }}\right)$ costs, according to [11]:

$$
C_{\text {health }}=C_{\text {direct }}+C_{\text {indirect }}+C_{\text {intangible }}
$$

Direct costs include health care and non-health care costs associated with treatment and caring. These costs are based on market values for e.g. medical staff, examinations, laboratory tests, medication, consumables and hospital facilities as well as for caregivers' time, and are estimated using bottom-up or top-down accounting methods [11].

Indirect costs include costs associated with loss of productivity due to morbidity as well loss of production due to morbidity or mortality. These costs are based on market values for e.g. wages, incomes and earnings, and are estimated using the human capital approach (HCA) or the friction cost approach (FCA) [11, 20]. The HCA approach assesses an individual's productivity and production losses from health deterioration, based on the time foregone from productive activities over the individual's lifetime and against the relevant wage rate [21]. The FCA approach assesses a firm's productivity and production losses from health deterioration, based on the time needed to restore initial production levels (friction period) and assuming vacancies are filled by unemployed (low opportunity cost) employees [22].

Finally, intangible costs include non-market costs associated with pain and suffering. These costs are based on non-market values for pain and suffering from morbidity and mortality, and are estimated using quality-adjusted-life-year (QALY) and willingness-to-pay (WTP) or willingness-to-accept (WTA) approaches [23]. The QALY approach assesses the change in QALYs, and corresponding monetary values, due to an expected change in health. Estimates are invariably dependent on life expectancy, future health and latency, though rarely dependent on income or risk characteristics [23]. The "willingness-to" approaches assess an individual's willingness to spend money for an expected health improvement (WTP; compensating variation) or, alternatively, an individual's willingness to receive money to forgo an expected health improvement (WTA; equivalent variation). Estimated values may be a function of income, education and age as well as environmental quality [12, 23].

\subsection{Overview of the research studies}

This section gathers scientific/technical information according to different health indicators (i.e. extent of health effects) associated to air pollution. For the reasons outlined in Section 3.1, only health effects due to particulate matter (PM2.5 and PM10) are presented (Table 1). Note, nonetheless, that health effects caused by other air pollutants (e.g. ozone, nitrogen oxides) should not be overlooked when the goal is to make a comprehensive health impact assessment. For each health indicator the following aspects are considered: affected age groups, exposure time, impact functions (as RR) and damage costs per unit. 
Table 1: Economic evaluation of health effects related to PM2.5 and PM10.

\begin{tabular}{|c|c|c|c|c|c|c|}
\hline \multirow{2}{*}{$\begin{array}{l}\text { Health effect } \\
\text { (pollutant) }\end{array}$} & \multirow{2}{*}{ Age group } & \multirow{2}{*}{$\begin{array}{l}\text { Study } \\
\text { design }\end{array}$} & \multirow{2}{*}{$\begin{array}{l}\text { Relative risk } \\
(95 \% \text { CI })\end{array}$} & \multicolumn{2}{|c|}{$\begin{array}{c}\text { External costs } \\
\text { (prices per unit) }\end{array}$} & \multirow{2}{*}{ Reference } \\
\hline & & & & $€$ (base year) & Unit & \\
\hline \multicolumn{7}{|c|}{ Morbidity } \\
\hline \multirow{4}{*}{ Cough (PM2.5) } & Children & & 0.22 & & & [18] \\
\hline & Adults & & 0.28 & & & [18] \\
\hline & Children $<16$ yr & & 0.45 & $59(2006)$ & Day & [9] \\
\hline & Adults $>15 \mathrm{yr}$ & & 0.28 & $59(2006)$ & Day & [9] \\
\hline \multirow{2}{*}{ Cough (PM10) } & Children & & 0.13 & & & [18] \\
\hline & Adults & & 0.17 & & & {$[18]$} \\
\hline Chronic cough (PM2.5) & Children & Long-term & $3.46 \mathrm{E}-03$ & & & {$[18]$} \\
\hline Chronic cough (PM10) & Children & Long-term & $2.07 \mathrm{E}-03$ & & & [18] \\
\hline \multirow{5}{*}{ Asthma (PM10) } & Children 5-19 yr & Short-term & $0.28(0.06-0.51)$ & & & [24] \\
\hline & Children < $15 \mathrm{yr}$ & & $0.44(0.27-0.62)$ & & & [25] \\
\hline & Adults $\geq 15 \mathrm{yr}$ & & $0.39(0.19-0.59)$ & & & [25] \\
\hline & & & & 31 & Day & [12] \\
\hline & & & & $85(2000)$ & Day & [26] \\
\hline $\begin{array}{l}\text { Acute bronchitis } \\
\text { (PM10) }\end{array}$ & Children & Short-term & & 131 & Day & {$[12]$} \\
\hline \multirow{2}{*}{ Bronchitis (PM10) } & Children $<15 \mathrm{yr}$ & & $3.06(1.35-5.02)$ & & & {$[25]$} \\
\hline & Children 6-18 yr & Long-term & $0.8(0-1.9)$ & & & {$[24]$} \\
\hline \multirow{2}{*}{$\begin{array}{l}\text { Chronic bronchitis } \\
\text { (PM2.5) }\end{array}$} & Adults & Long-term & $3.90 \mathrm{E}-05$ & & & {$[18]$} \\
\hline & Adults & & $8.20 \mathrm{E}-0.5$ & $52,962(2006)$ & Case & [9] \\
\hline \multirow{3}{*}{$\begin{array}{l}\text { Chronic bronchitis } \\
\text { (PM10) }\end{array}$} & Adults & & $2.45 \mathrm{E}-0.5$ & & & [18] \\
\hline & Adults $>18 \mathrm{yr}$ & Long-term & $1.17(0.40-1.89)$ & & & {$[24]$} \\
\hline & Adults $>27 \mathrm{yr}$ & & $0.98(0.09-1.94)$ & & & {$[25]$} \\
\hline \multirow{4}{*}{$\begin{array}{l}\text { Chronic bronchitis } \\
\text { incidence (PM10) }\end{array}$} & Adults $>27 \mathrm{yr}$ & & $2.65 \mathrm{E}-0.5$ & $\begin{array}{c}153,000 \\
(2002)\end{array}$ & Case & {$[27]$} \\
\hline & & & & $\begin{array}{c}168,840 \\
(2000)\end{array}$ & Case & [26] \\
\hline & Adults & & & 209,000 & Case & {$[12]$} \\
\hline & & & & 190,000 & Case & {$[6]$} \\
\hline \multirow{2}{*}{$\begin{array}{c}\text { Congestive heart failure } \\
\text { (PM2.5) }\end{array}$} & & & $3.09 \mathrm{E}-05$ & & & [18] \\
\hline & Over 65 & & 3.09E-05 & $16,409(2006)$ & Case & [9] \\
\hline \multirow{2}{*}{$\begin{array}{l}\text { Congestive heart failure } \\
\text { (PM10) }\end{array}$} & Over 65 & & $1.85 \mathrm{E}-05$ & & & {$[18]$} \\
\hline & Over 65 & & & $3,360(2000)$ & Case & [26] \\
\hline \multirow{3}{*}{$\begin{array}{l}\text { Respiratory HA } \\
\text { (PM2.5) }\end{array}$} & All ages & & $3.46 \mathrm{E}-06$ & & & [18] \\
\hline & All ages & Short-term & $0.19(0-0.40)$ & & & [24] \\
\hline & & & $3.46 \mathrm{E}-06$ & $7,931(2006)$ & Case & [9] \\
\hline \multirow{4}{*}{$\begin{array}{l}\text { Respiratory HA } \\
\text { (PM10) }\end{array}$} & All ages & & $2.07 \mathrm{E}-06$ & & & {$[18]$} \\
\hline & All ages & & 7.03E-03 & $1,900(2002)$ & Case & [27] \\
\hline & All ages & & $0.13(0.01-0.25)$ & & & {$[25]$} \\
\hline & & Short-term & 0.08 & $\begin{array}{c}3,313-13,633 \\
(2012)\end{array}$ & Case & [28] \\
\hline \multirow{2}{*}{ Respiratory HA } & All ages & & & $4,400(2000)$ & Case & [26] \\
\hline & & & & $1,604(2003)$ & Case & [3] \\
\hline \multirow[t]{3}{*}{$\begin{array}{c}\text { Cardiovascular HA } \\
\text { (PM2.5) }\end{array}$} & All ages & Short-term & $0.091(0.017-0.166)$ & & & [24] \\
\hline & All ages & & $4.34 \mathrm{E}-06$ & $1,900(2002)$ & Case & {$[27]$} \\
\hline & All ages & & $0.13(0.07-0.19)$ & & & [25] \\
\hline \multirow{3}{*}{$\begin{array}{l}\text { Cardiovascular HA } \\
\text { (PM10) }\end{array}$} & All ages & Short-term & 0.08 & $\begin{array}{c}3,822-12,614 \\
(2012)\end{array}$ & Case & [28] \\
\hline & All ages & Short-term & $0.06(0.03-0.09)$ & & & [18] \\
\hline & All ages & Short-term & $0.09(0.04-0.15)$ & & & [29] \\
\hline Cardiovascular HA & & & & $5,106(2003)$ & Case & [3] \\
\hline
\end{tabular}


Table 1: Continued.

\begin{tabular}{|c|c|c|c|c|c|c|}
\hline \multirow{2}{*}{$\begin{array}{c}\text { Health effect } \\
\text { (pollutant) }\end{array}$} & \multirow[t]{2}{*}{ Age group } & \multirow{2}{*}{$\begin{array}{l}\text { Study } \\
\text { design }\end{array}$} & \multirow{2}{*}{$\begin{array}{l}\text { Relative risk } \\
(95 \% \mathrm{CI})\end{array}$} & \multicolumn{2}{|c|}{$\begin{array}{l}\text { External costs } \\
\text { (prices per unit) }\end{array}$} & \multirow[t]{2}{*}{ Reference } \\
\hline & & & & $€$ (base year) & Unit & \\
\hline \multicolumn{7}{|c|}{ Mortality } \\
\hline \multirow{2}{*}{ Lung cancer (PM2.5) } & & & $1.3(0.4-2.2)$ & & Case & [15] \\
\hline & & & $1.26 \mathrm{E}-05$ & $21,152(2006)$ & Case & [9] \\
\hline $\begin{array}{l}\text { Respiratory mortality } \\
\text { (PM10) }\end{array}$ & All ages & Short-term & $0.13(0.05-2.0)$ & & & [19] \\
\hline $\begin{array}{l}\text { Cardiopulmonary } \\
\text { mortality (PM2.5) }\end{array}$ & Adults $>30 \mathrm{yr}$ & Long-term & $0.8(0.2-1.4)$ & & Case & {$[15,19]$} \\
\hline $\begin{array}{c}\text { Cardiovascular } \\
\text { mortality (PM10) }\end{array}$ & All ages & Short-term & $0.09(0.05-1.3)$ & & & [19] \\
\hline $\begin{array}{l}\text { Acute mortality } \\
\text { (PM2.5) }\end{array}$ & & & 0.068 & & & [18] \\
\hline $\begin{array}{l}\text { Acute mortality } \\
\text { (PM10) }\end{array}$ & & & 0.04 & & & {$[18]$} \\
\hline \multirow{2}{*}{$\begin{array}{l}\text { Chronic mortality } \\
\text { (PM2.5) } \\
\text { Chronic mortality } \\
\text { (PM10) }\end{array}$} & Adults $>30 \mathrm{yr}$ & & $1.138 \mathrm{E}-0.3$ & 77,199 (2006) & YOLL & [9] \\
\hline & All ages & & $4.00 \mathrm{E}-04$ & $\begin{array}{l}40,300(2002) \\
44,595(2012)\end{array}$ & $\begin{array}{l}\text { Case } \\
\text { Case } \\
\end{array}$ & $\begin{array}{l}{[27]} \\
{[28]}\end{array}$ \\
\hline \multirow{3}{*}{$\begin{array}{l}\text { Total mortality - All } \\
\text { causes (PM2.5) }\end{array}$} & $\begin{array}{l}\text { Age }>9 \\
\text { months }\end{array}$ & & $6.68 \mathrm{E}-06$ & $3,167,832(2006)$ & Case & [9] \\
\hline & Adults $>30 \mathrm{yr}$ & Long-term & $0.6(0.2-1.0)$ & 63,447 & Case & {$[15,19]$} \\
\hline & Adults $>30 \mathrm{yr}$ & Long-term & $0.62(0.40-0.83)$ & & & [24] \\
\hline \multirow{3}{*}{$\begin{array}{l}\text { Total mortality - All } \\
\text { causes (PM10) }\end{array}$} & Áge $<1$ yr & Long-term & $0.4(0.2-0.7)$ & & & {$[19,24]$} \\
\hline & Adults $>30 \mathrm{yr}$ & & $0.43(0.26-0.61)$ & & & {$[19,25]$} \\
\hline & All ages & Short-term & $\begin{array}{c}0.123 \\
(0.045-0.201)\end{array}$ & & & {$[24]$} \\
\hline
\end{tabular}

RR per $\mu \mathrm{g} \cdot \mathrm{m}^{-3} /$ person/year

Hurley et al. [18] used the ExternE impact functions (RR)

For long-term studies are often used annual mean concentrations

HA: Hospital admissions $\quad$ YOLL: Year of life lost

Results show that largest relative risk impacts from PM air pollution are associated with cough, asthma, cardiovascular HA, as well as cardiopulmonary mortality. External costs of morbidity are largest for bronchitis, congestive heart failure and respiratory and cardiovascular HA. In relation to mortality costs, they vary between 21 and 77 thousand Euro per case for adults over 30 years of age. Based on these results, it is expected that largest external costs from PM air pollution are related with cardiovascular health problems.

On the other hand, for certain health indicators, the pollutant effect on a given age group reveals considerable variations in terms of impact functions (i.e. ERF) and external costs, which can be explained by the differing methodologies, the geographical coverage and socio-economic conditions across studies. These research studies are designed to Europe as a whole [9, 24], however some outcomes are more specific, namely the works developed by DEFRA [28] for the UK and Seethaler [25], multi-national study of Austria, France and Switzerland.

Concerning the ERF, this variability may be associated to several factors, namely the population structure (density, affected age groups and their distribution), source of data gathering and for certain health indicators routinely gathered data can be unavailable or may not be in the proper form to be used in economic valuation. 
Moving from extent of health impacts to economic costs, the variability in external cost estimates is particularly large when these are grounded on WTP studies. WTP studies are based on interviews in which personal interpretation of the questions as well as strategic behaviour by respondents can lead to biased outcomes [11]. Furthermore, these values might also depend on additional variables, such as income and age, and probably differ between health effects [19]. The WTP approach has the advantage of acquiring the full range of personal costs associated with the disease [11]. Nevertheless, this monetary valuation should be carefully considered as many of those effects have no market value [26]. As a consequence or not, several health effects due to air pollution are often neglected, and the results are probably an underestimation of the total health costs [19].

\section{Concluding remarks}

The key issues to estimate health costs derived from air pollution are broadly related with two different concerns: how to identify all physical impacts, and how these impacts can be converted in monetary values. Aiming these issues, many studies have been developed. However, it is evident that none of these research works is complete, since they omit some measurable cost components and have limitations with respect to the methods used in estimating damage costs. In order to overcome these methodological weaknesses, further research is essential to improve the health impact assessment related with air pollution, contributing to decrease the uncertainties. As priority action areas the following ideas are commonly recognized by the scientific community:

- to explore the human exposure at personal level and in different microenvironments;

- to investigate the health impact due to exposure to multiple pollutants (cocktail effect);

- to improve the coverage of potentially important effects in cost-benefit studies of air pollution control programs;

- with regards to monetary valuation of health impacts, further empirical studies need to be undertaken, aiming to assess the cost elements integrating the individual WTP.

Based on this research underpinned in current scientific knowledge, the next stage of MAPLIA project will be the estimation of the health impacts and related costs of different air quality improvement scenarios and perform the cost-benefit analysis. The main outcomes will be used to policy support of decision-making in air quality management issues.

\section{Acknowledgement}

This work was supported by European funds through the COMPETE Programme and the National funds from FCT - Science and Technology Portuguese Foundation within project PEst-C/MAR/LA0017/2013 for the MAPLIA Project (PTDC/AAG-MAA/4077/2012). 


\section{References}

[1] Carnevale, C., Finzi, G., Pisoni, E., Volta, M., Guariso, G., Gianfreda, R., Maffeis, G., Thunis, P., White, L. \& Triacchini, G., An integrated assessment tool to define effective air quality policies at regional scale. Environmental Modelling \& Software, 38, pp. 306-315, 2012.

[2] International Institute for Applied Systems Analysis (IIASA). The Greenhouse Gas and Air Pollution Interactions and Synergies (GAINS) Model, Laxenburg, Austria. http://gains.iiasa.ac.at/models/.

[3] Department for Environment, Food and Rural Affairs (DEFRA), Valuation of the external costs and benefits to health and environment of waste management options, final report for DEFRA by Enviros Consulting Limited in association with EFTEC, London, UK, 2004.

[4] van Essen, H., Schroten, A., Otten, M., Sutter, D., Schreyer, C., Zandonella, R., Maibach, M., Doll, C., External Costs of Transport in Europe, Update Study for 2008, CE Delft, Netherlands, 2011.

[5] European Commission (EC), ExternE Externalities of Energy Methodology 2005 Update, Office for Official Publications of the European Communities, Edited by Peter Bickel and Rainer Friedrich, EUR 21951 EN, 2005.

[6] Holland, M., Hunt, A., Hurley, F., Navrud, S., Watkiss, P., Methodology for the Cost-Benefit Analysis for CAFE - Volume 1: Overview of Methodology, AEA Technology Environment, Didcot, UK, 2005.

[7] Miranda, A., Silveira, C., Ferreira, J., Monteiro, A., Lopes, D., Relvas, H., Borrego, C., Roebeling, P., Current air quality plans in Europe designed to support air quality management policies. Atmospheric Pollution Research, Critical Literature Review (In Press), 2015.

[8] Costa, S., Ferreira, J., Silveira, C., Costa, C., Lopes, D., Relvas, H., Borrego, C., Roebeling, P., Miranda, A.I., Teixeira, J.P., Integrating Health on Air Quality Assessment-Review Report on Health Risks of Two Major European Outdoor Air Pollutants: PM and NO2. Journal Of Toxicology And Environmental Health-part B-critical Reviews, 17(6), pp. 307-340, 2014.

[9] Brandt, J., Silver, J.D., Christensen, J.H., Andersen, M.S., Bønløkke, J.H., Sigsgaard, T., Geels, C., Gross, A., Hansen, A.B., Hansen, K.M., Hedegaard, G.B., Kaas, E., Frohn, L.M., Contribution from the ten major emission sectors in Europe and Denmark to the health-cost externalities of air pollution using the EVA model system - an integrated modelling approach. Atmospheric Chemistry Physics, 13, pp. 7725-7746, 2013.

[10] Wang, X., Mauzerall, D.L., Evaluating impacts of air pollution in China on public health: Implications for future air pollution and energy policies. Atmospheric Environment, 40, pp. 1706-1721, 2006.

[11] Pervin, T., Gerdtham, Ulf-G, Lyttkens, C.H., 2008. Societal costs of air pollution-related health hazards: A review of methods and results. Cost Effectiveness and Resource Allocation, 6(19), p. 22, 2008.

[12] Seethaler, R.K., Künzli, N., Sommer, H., Chanel, O., Herry, M., Masson, S., Vernaud, J-C., Filliger, P., Horak, F.Jr., Kaiser, R., Medina, S., 
Puybonnieux-Texier, V., Quénel, P., Schneider, J., Studnicka, M., Heldstab, J., Economic costs of air pollution-related health impacts: An impact assessment project of Austria, France and Switzerland. Clean Air and Environmental Quality, 37(1), pp. 35-43, 2003.

[13] Environment and Health Administration (EHA), The Stockholm Trial: Effects on air quality and health, report SLB 4:2006, Stockholm, p. 62, 2006.

[14] Ruckerl, R., Schneider, A., Breitner, S., Cyrys, J., and Peters, A., Health effects of particulate air pollution: A review of epidemiological evidence. Inhal. Toxicol. (23), pp. 555-592, 2011.

[15] Mechler, R., Amann, M., Schöpp, W., A methodology to estimate changes in statistical life expectancy due to the control of particulate matter air pollution, Interim Report IR-02-035 on work of the IIASA, Laxenburg, Austria, p. 41, 2002.

[16] World Health Organization (WHO), Health effects of particulate matter: Policy implications for countries in Eastern Europe, Caucasus and central Asia, WHO Regional Office for Europe, Geneva, p. 20, 2013 a.

[17] Marques, R.C., Cruz, N.F., Simões, P., Ferreira, S.F., Pereira, M.C., EIMPack - Economic Impact of the Packaging and Packaging Waste Directive, Task 5 - Environmental Valuation (Literature Rieview), work programme financed by European Investment Bank, Instituto Superior Técnico, Lisbon, Portugal, p. 57, 2013.

[18] Hurley, F., Hunt, A., Cowie, H., Holland, M., Miller, B., Pye, S., Watkiss, P., Methodology for the Cost-Benefit Analysis for CAFE-Volume 2: Health Impact Assessment, AEA Technology Environment, Didcot, UK, 2005.

[19] World Health Organization (WHO), Economic valuation of transportrelated health effects: Review of methods and development of practical approaches, with a special focus on children, WHO Regional Office for Europe, Copenhagen, Denmark, 2008.

[20] Hanly, P., Timmons, A., Walsh, P.M., Sharp, L., Breast and Prostate Cancer Productivity Costs: A Comparison of the Human Capital Approach and the Friction Cost Approach. Value in health, 15, pp. 429-436, 2012.

[21] Tranmer, J.E., Guerriere, D.N., Ungar, W.J., Coyte, P.C., Valuing patient and caregiver time: a review of the literature. Pharmacoeconomics, 23(5), pp. 449-459, 2005.

[22] Koopmanschap, M.A., van Ineveld, B.M., Towards a new approach for estimating indirect costs of disease. Soc Sci Med, 34(9), pp. 1005-1010, 1992.

[23] Hammitt, J.K., Methodological Review of WTP and QALY Frameworks for Valuing Environmental Health Risks to Children, report prepared for the OECD Project on the "Valuation of Environment-Related Health Impacts, with a Particular Focus on Children", Harvard University, USA, 2007.

[24] World Health Organization (WHO), Recommendations for concentrationresponse functions for cost-benefit analysis of particulate matter, ozone and nitrogen dioxide, Health risks of air pollution in Europe-HRAPIE project, WHO Regional Office for Europe, Copenhagen, Denmark, p. 54, $2013 \mathrm{~b}$. 
[25] Seethaler, R., Health Costs due to Road Traffic-related Air Pollution: An impact assessment project of Austria, France and Switzerland, Synthesis Report published by Federal Department of Environment, Transport, Energy and Communications, Berne, Switzerland, p. 105, 1999.

[26] Belhaj, M., Fridell. E., External Costs in the Transport Sector: A Literature Review, The Swedish Environmental Research Institute, Stockholm, Sweden, 2010.

[27] Maibach, M., Schreyer, C., Sutter, D., van Essen, H.P., Boon, B.H., Smokers, R., Schroten, A., Doll, C., Pawlowska, B., Bak, M., Handbook on estimation of external costs in the transport sector, report produced within the study Internalisation Measures and Policies for All external Cost of Transport (IMPACT), Version 1.1, CE Delft, p. 332, 2008.

[28] Department for Environment, Food and Rural Affairs (DEFRA), Impact pathway guidance for valuing changes in air quality, London, UK, p. 20, 2013.

[29] Ballester, F., Rodríguez, P., Iñíguez, C., Saez, M., Daponte, A., Galán, I., Taracido, M., Arribas, F., Bellido, J., Cirarda, F. B., Cañada, A., Guillén, J. J., Guillén-Grima, F., López, E., Pérez-Hoyos, S., Lertxundi, A., Toro, S., Air pollution and cardiovascular admissions association in Spain: Results within the EMECAS project. J. Epidemiol. Commun. Health, 60, pp. 328336, 2006. 